\title{
Comorbid insomnia and sleep apnea: a prevalent but overlooked disorder
}

\author{
Matthew S. Brock ${ }^{1} \cdot$ Vincent Mysliwiec ${ }^{1}$
}

Received: 13 November 2017 / Revised: 4 January 2018 / Accepted: 11 January 2018 /Published online: 25 January 2018

(C) This is a U.S. Government work and not under copyright protection in the US; foreign copyright protection may apply 2018

\section{Dear Editor:}

Comorbid insomnia and obstructive sleep apnea (OSA) was first described 45 years ago and was well characterized by Krakow and colleagues in 2001 [1-3]. Despite the realization that this comorbidity was under-recognized and had implications for disease-related outcomes, little has changed in the ensuing years [4]. In this issue of Sleep and Breathing, there are three articles in veteran populations which substantially further our understanding of this disorder.

Using a modification to the Insomnia Severity Index (ISI), Wallace et al. reported that $47 \%$ of US veterans who underwent an initial evaluation for OSA had insomnia. Specifically, they required a score $\geq 6$ on the first three questions, which assesses difficulties in falling asleep, staying asleep, or awakening too early and are consistent with moderate insomnia symptoms. Another major finding from their study is that patients with comorbid early and late insomnia symptoms and OSA are less adherent to positive airway pressure (PAP) at 6 months. In the paper by El-Solh et al., the effect of insomnia on US veterans with posttraumatic stress disorder (PTSD) and OSA was assessed. They also used the ISI with the standard threshold score $\geq 15$ to classify patients as having insomnia. In this study, veterans with comorbid insomnia were more likely to have depression, decreased quality of life, and worse sleep quality on polysomnography (PSG). Similar to the findings of Wallace et al., the veterans with comorbid insomnia, OSA, and PTSD were significantly less adherent to PAP and also had no

This article is part of the Topical Collection on Comorbid Insomnia and OSA (COMISA) in Veterans

All work was performed at Wilford Hall Ambulatory Surgical Center, JBSA-Lackland, TX 78236.

Vincent Mysliwiec

Vincent.mysliwiec.mil@mail.mil

1 Department of Sleep Medicine, San Antonio Military Medical Center, 1100 Wilford Hall Loop, Bldg 4554,

JBSA-Lackland, TX 78236, USA improvements in overall sleep quality. In the third paper, Rezaeitalab et al. found that insomnia, diagnosed by clinical interview, was the most frequent symptom in Iranian veterans with PTSD and OSA; this was despite nearly all patients taking medications for insomnia at the time of their evaluation.

There are a number of studies which report on the prevalence of comorbid insomnia and OSA with rates ranging from $13.8 \%$ in patients with moderate to severe OSA in a general sleep clinic to as high $90.9 \%$ in crime victims with nightmares and PTSD $[2,3,5,6]$. The wide range in prevalence is in part due to the difference in patient populations, but another reason is the variation in study methodology. Studies assessing this comorbidity have typically taken one of two approaches, evaluating patients with known OSA for insomnia or patients with insomnia for the presence of sleep disordered breathing. The patient populations differ based on which diagnosis was initially studied and thus, which diagnosis is considered comorbid. The overlap of shared symptoms between the two conditions further complicates making the diagnosis. Utilization of different criteria to diagnose sleep apnea [7] as well as differing nocturnal and daytime features to diagnose insomnia, including self-reported symptoms [8] and objective PSG parameters [9], has also contributed to this variability.

The high prevalence of comorbid insomnia and OSA and significantly lower PAP adherence in patients with both disorders compared to OSA alone underscore the need for a standardized systematic approach to identifying and treating these sleep disorders when they co-occur. Several barriers to standardization exist. First, the nosology in the literature is inconsistent with terminology including OSA-insomnia [9], complex insomnia [2], and comorbid insomnia and OSA among others. This inconsistency creates confusion and further highlights the variability that exists in diagnosing comorbid insomnia and OSA. The recently used acronym "COMISA" for comorbid insomnia and sleep apnea conveys the presence of both conditions in a memorable and potentially unifying term [10].

Another barrier to recognizing COMISA is the absence of standard diagnostic criteria for this disorder. Wallace et al. 
used questions from the ISI that focused on nocturnal manifestations of insomnia as opposed to daytime characteristics that often overlap with symptoms of OSA whereas El-Solh used the standard cut-off score. Either of these straightforward approaches could be implemented for all patients undergoing a PSG for suspected OSA. Validating the method used by Wallace et al. or a similar questionnaire that assesses insomnia symptoms at the time of a PSG could ultimately lead to standardized diagnostic criteria for COMISA. However, the question remains regarding the corollary to this, as to how patients with insomnia should be evaluated for OSA. Is the best way to evaluate OSA in insomnia patients to use a validated questionnaire such as the Berlin or STOP-BANG, an attended inlab PSG, or do we continue with current practice of obtaining a PSG when occult sleep disordered breathing is suspected and/or patients prove refractory to standard insomnia treatment?

Overall, adherence to PAP therapy in OSA remains suboptimal, with most studies reporting rates of approximately $50 \%$ [11]. Certain populations have even lower adherence rates, noting adherence to PAP in patients with OSA and PTSD was 30.2 versus $55.1 \%$ in those with OSA alone [12]. Further, El Solh et al. revealed that patients with COMISA and PTSD had markedly less PAP adherence (32.9\%) than those with OSA and PTSD (49.5\%). Thus are the low rates of PAP adherence in patients with OSA and PTSD from PTSD, insomnia symptoms, or a combination of these disorders?

The assessment of comorbid insomnia, which is highly prevalent in OSA patients, both with and without behavioral medicine disorders, is not routine nor necessarily recommended in patients who are not adherent to PAP. In articles specifically addressing PAP adherence, references to insomnia are infrequent and limited, noting that "insomnia complaints are common in older adults and patients with insomnia may also have difficulty adapting to CPAP" or that insomnia can be a side effect of PAP [13, 14]. Similarly, many patients with insomnia have an inadequate response to pharmacologic therapy, as was present in the article by Rezaeitalab et al., and cognitive behavioral therapy for insomnia (CBTi). In a metaanalysis of CBTi in comorbid medical and psychiatric disorders, only $36 \%$ of patients were in remission after treatment [15]. Supporting the role that "occult" sleep disordered breathing is present in many patients with refractory insomnia is an article by Krakow et al. that reported $90 \%$ of nocturnal awakenings in patients with chronic insomnia only (no suspicion of OSA) were due to respiratory events [16]. Clearly, a higher clinical suspicion for COMISA is required in patients with sleep disturbances as their presentation is not always classic.

The optimal way to treat COMISA once it is identified has been an area of debate with evidence supporting a stepwise treatment approach beginning with OSA with PAP [17] or insomnia with CBTi [18] as well as concurrent combined therapy [19]. There is currently one ongoing study evaluating CBTi followed by PAP, compared to concurrent $\mathrm{CBTi}$ and PAP versus PAP alone [20]. However, pending this and future studies, a multidisciplinary approach integrating behavioral sleep medicine would seem the most effective way to ensure that symptoms of both insomnia and OSA are addressed [21, 22]. Future research and guidelines should focus not only on a standardized approach to diagnose COMISA but also on determining the optimal way to treat this increasingly recognized phenomenon in sleep medicine. As insomnia and OSA are the two most prevalent sleep disorders, it may be appropriate to evaluate all patients with sleep disturbances for COMISA.

Compliance with ethical standards No clinical trial was performed.

Conflict of interest The authors declare that they have no conflict of interest.

Disclaimer The opinions and assertions in this manuscript are those of the authors and do not represent those of the Department of the Air Force, Department of Defense, or the US government.

\section{References}

1. Guilleminault C, Eldridge FL, Dement WC (1973) Insomnia with sleep apnea: a new syndrome. Science 181(4102):856-858. https:// doi.org/10.1126/science.181.4102.856

2. Krakow B, Melendrez D, Pedersen B, Johnston L, Hollifield M, Germain A, Koss M, Warner TD, Schrader R (2001) Complex insomnia: insomnia and sleep-disordered breathing in a consecutive series of crime victims with nightmares and PTSD. Biol Psychiatry 49(11):948-953. https://doi.org/10.1016/S0006-3223(00)01087-8

3. Krakow B, Melendrez D, Ferreira E, Clark J, Warner TD, Sisley B, Sklar D (2001) Prevalence of insomnia symptoms in patients with sleep-disordered breathing. Chest 120(6):1923-1929. https://doi. org/10.1378/chest.120.6.1923

4. Al-Jawder SE, BaHammam AS (2012) Comorbid insomnia in sleeprelated breathing disorders: an under-recognized association. Sleep Breath 16(2):295-304. https://doi.org/10.1007/s11325-011-0513-1

5. Mysliwiec V, Gill J, Lee H, Baxter T, Pierce R, Barr TL, Krakow B, Roth BJ (2013) Sleep disorders in US military personnel: a high rate of comorbid insomnia and obstructive sleep apnea. Chest 144(2):549-557. https://doi.org/10.1378/chest.13-0088

6. Fung CH, Martin JL, Dzierzewski JM, Jouldjian S, Josephson K, Park M, Alessi C (2013) Prevalence and symptoms of occult sleep disordered breathing among older veterans with insomnia. J Clin Sleep Med 9(11):1173-1178. https://doi.org/10.5664/jcsm.3162

7. Lichstein KL, Riedel BW, Lester KW, Aguillard RN (1999) Occult sleep apnea in a recruited sample of older adults with insomnia. $\mathrm{J}$ Consult Clin Psychol 67(3):405-410. https://doi.org/10.1037/ 0022-006X.67.3.405

8. Björnsdóttir E, Janson C, Sigurdsson JF, Gehrman P, Perlis M, Juliusson S, Arnardottir ES, Kuna ST, Pack AI, Gislason T, Benediktsdóttir B (2013) Symptoms of insomnia among patients with obstructive sleep apnea before and after two years of positive airway pressure treatment. Sleep 36(12):1901-1909. https://doi. org/10.5665/sleep.3226 
9. Smith S, Sullivan K, Hopkins W, Douglas J (2004) Frequency of insomnia report in patients with obstructive sleep apnoea hypopnea syndrome (OSAHS). Sleep Med 5(5):449-456. https://doi.org/10. 1016/j.sleep.2004.03.005

10. Sweetman AM, Lack LC, Catcheside PG, Antic NA, Chai-Coetzer CL, Smith SS, Douglas JA, McEvoy RD (2017) Developing a successful treatment for co-morbid insomnia and sleep apnoea. Sleep Med Rev 33:28-38. https://doi.org/10.1016/j.smrv.2016.04.004

11. Weaver TE, Grunstein RR (2008) Adherence to continuous positive airway pressure therapy: the challenge to effective treatment. Proc Am Thorac Soc 5(2):173-178. https://doi.org/10.1513/pats. 200708-119MG

12. Lettieri CJ, Williams SG, Collen JF (2016) OSA syndrome and posttraumatic stress disorder: clinical outcomes and impact of positive airway pressure therapy. Chest 149(2):483-490. https://doi. org/10.1378/chest.15-0693

13. Sawyer AM, Gooneratne NS, Marcus CL, Ofer D, Richards KC, Weaver TE (2011) A systematic review of CPAP adherence across age groups: clinical and empiric insights for developing CPAP adherence interventions. Sleep Med Rev 15(6):343-356. https://doi. org/10.1016/j.smrv.2011.01.003

14. Kushida CA, Littner MR, Hirshkowitz M, Morgenthaler TI, Alessi CA, Bailey D, Boehlecke B, Brown TM, Coleman J Jr, Friedman L, Kapen S (2006) Practice parameters for the use of continuous and bilevel positive airway pressure devices to treat adult patients with sleep-related breathing disorders. Sleep 29(3):375-380. https://doi. org $/ 10.1093 /$ sleep/29.3.375

15. Wu JQ, Appleman ER, Salazar RD, Ong JC (2015) Cognitive behavioral therapy for insomnia comorbid with psychiatric and medical conditions: a meta-analysis. JAMA Intern Med 175(9):14611472. https://doi.org/10.1001/jamainternmed.2015.3006
16. Krakow B, Romero E, Ulibarri VA, Kikta S (2012) Prospective assessment of nocturnal awakenings in a case series of treatmentseeking chronic insomnia patients: a pilot study of subjective and objective causes. Sleep 35(12):1685-1692. https://doi.org/10.5665/ sleep. 2244

17. Bjornsdottir E, Janson C, Arnardóttir E, Pack A, Gíslason T, Benediktsdottir B (2013) Symptoms of insomnia among OSA patients before and after 2 years of PAP treatment. Sleep Med 14:e74. https://doi.org/10.1016/j.sleep.2013.11.148

18. Guilleminault C, Davis K, Huynh NT (2008) Prospective randomized study of patients with insomnia and mild sleep disordered breathing. Sleep 31(11):1527-1533. https://doi.org/10.1093/sleep/ 31.11 .1527

19. Wickwire EM, Schumacher JA, Richert AC, Sinan Baran A, Roffwarg HP (2008) Combined insomnia and poor CPAP compliance: a case study and discussion. Clinical Case Studies 7(4):267286. https://doi.org/10.1177/1534650107309187

20. Multidisciplinary Approach to the Treatment of Insomnia and Comorbid Sleep Apnea (MATRICS). ClinicalTrials.gov Identifier NCT01785303 https://www.clinicaltrials.gov/ct2/show/ NCT01785303?term $=$ insomnia\&cond $=0$ sa\&rank $=3$. Accessed 28 Dec 2017

21. Wickwire EM, Lettieri CJ, Cairns AA, Collop NA (2013) Maximizing positive airway pressure adherence in adults: a common-sense approach. Chest 144(2):680-693. https://doi.org/ $10.1378 /$ chest.12-2681

22. Ong JC, Crawford MR, Kong A, Park M, Cvengros JA, Crisostomo MI, Alexander EI, Wyatt JK (2017) Management of obstructive sleep apnea and comorbid insomnia: a mixed-methods evaluation. Behav Sleep Med 15(3):180-197. https://doi.org/10.1080/ 15402002.2015.1087000 